\title{
10th Anniversary of the Beijing SHRIMP Centre, China
}

The Beijing SHRIMP Centre (BSC) celebrates its 10th Anniversary on 18 December 2011. It has become known as one of the most successful ion microprobe laboratories world-wide and is a world-class platform for isotopic dating. It has helped countless scientists to resolve critical geological problems and thus greatly promoting the development of the geological sciences in and outside China. It was opened on 18 December in 2001 as a National Analytical Facility through funding from the Chinese Ministries of Science and Technology and Land and Resources and is incorporated into the Institute of Geology, Chinese Academy of Geological Sciences (CAGS) in Beijing. It was established on the initiative of its Director, Prof. Dunyi Liu who, in 1979, was one of the first young Chinese scientists to study abroad as a Visiting Research Fellow at the Research School of Earth Sciences of the Australian National University in Canberra, Australia. At that time, a group of scientists led by Prof. William Compston had designed and developed, through 10 years of meticulous research and engineering, a sensitive, high-resolution ion microprobe which they named SHRIMP I and which revolutionized geochronology in being able to precisely date tiny spots on zircons and other U-bearing minerals. Dunyi was able to participate in the use and further development of this new instrument and undertook research on Archaean rocks in China while based in Canberra. He realized the potential and importance of this instrument for the geosciences in China and, in 1994, began to lobby for financial support to establish the BSC.

In the following years the ion microprobe technology had been developed further, and in May 2001 the SHRIMP II instrument, manufactured by Australian Scientific Instruments Pty. Ltd. in Canberra, was delivered to Beijing, installed and tested, and became operational in December 2001 (Fig. 1) together with rock crushing and mineral separation facilities, mount making and polishing, as well as cathodoluminescence and back-scatter imaging. At that time the BSC consisted of ten research scientists and technicians, and this has now risen to 23 (Fig. 2). The major objectives of the Centre are to provide high-quality geochronological and cosmochronological data, develop new techniques for SHRIMP dating and mineral geochemistry, undertake research in Precambrian geochronology and crustal evolution and the composition and evolution of the Phanerozoic orogenic belts in Central and Eastern Asia. Furthermore, the BSC trains post-graduate $\mathrm{MSc}$ and $\mathrm{PhD}$

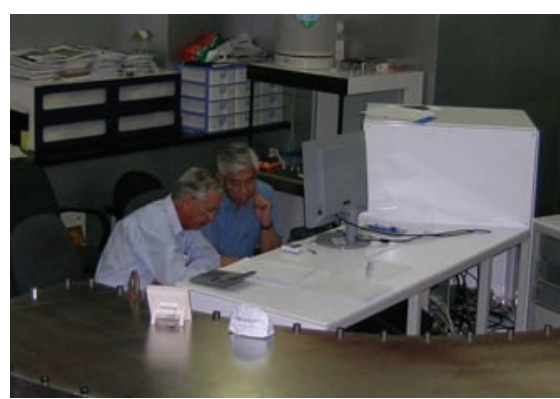

Fig. 1. Profs. William Compston (left) and Dunyi Liu (right) discussing technical details during analytical session on SHRIMP II in the Beijing Laboratory.

students as well as engineers and technicians. Established techniques are the dating of zircon, monazite, rutile, apatite, merrilite, and opal as well as in-situ REE analyses of zircon. The dating of very young zircons and of fluorite are under development.

The SHRIMP laboratory has played a very important role in earth science research in China which is evident from the increasing number of publications in international geoscience journals reporting SHRIMP zircon ages and stable isotope data. For example, in 2003 there were 33 publications in Chinese journals and 4 in international journals resulting from data produced at the BSC. This number rose steadily, and in 2009 there were 132 publications in Chinese and 68 in international journals. The impact of the BSC on international visibility and quality of Chinese geoscience research is also evident from the fact that in the first few years of this century, when Chinese papers in western journals were still rare, many of those published contained zircon ages produced at the Beijing SHRIMP Laboratory.

From its inception it was the policy of Dunyi Liu to make the SHRIMP II facility available to researchers from anywhere in China and abroad, and numerous scientists have visited the Centre over the years. During the period $2002-2010$ some $25 \%$ of the analytical time on SHRIMP II was used by scientists of the Institute of Geology of CAGS, $22 \%$ by scientists of other institutions of the Ministry of Land and Resources such as the Geological Survey of China, 22\% by researchers from mainland Chinese universities, $16 \%$ by scientists of the Chinese Academy of Sciences, $10 \%$ by researchers from foreign institutions, $4 \%$ by scientists from Hong Kong and Taiwan, and a mere $1 \%$ by other governmental institutions in China. The enormous scientific output of the

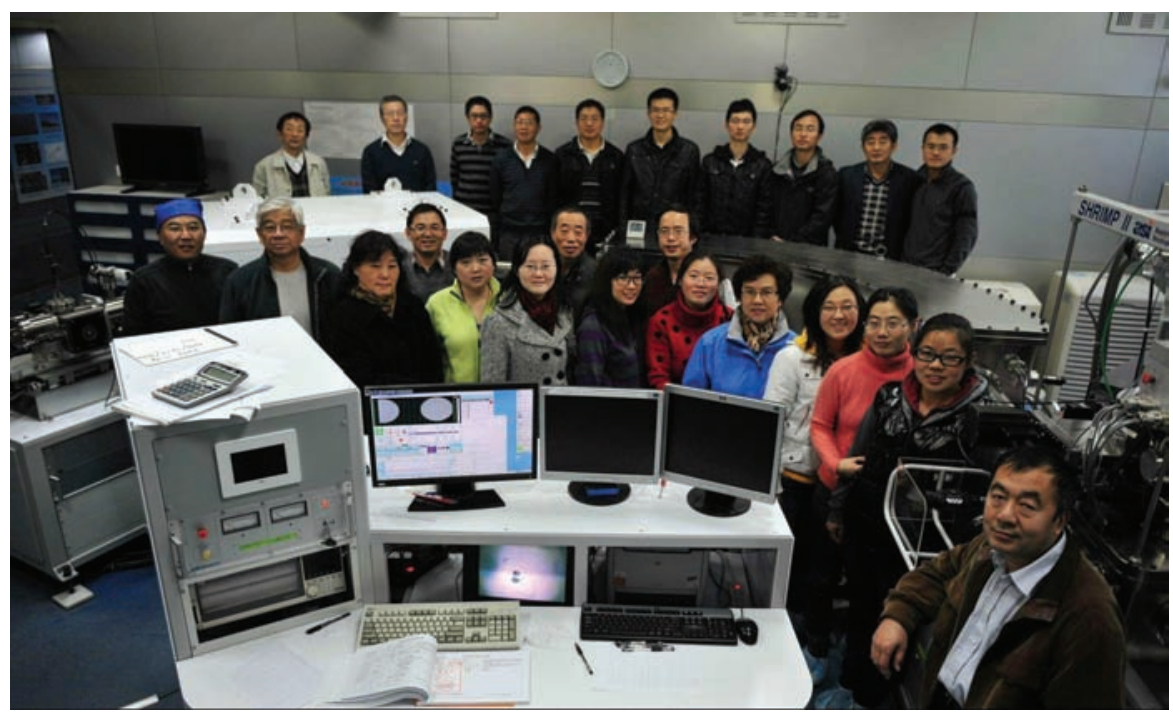

Figure 2. Research, technical and administrative staff of the Beijing SHRIMP Centre in November 2011. Front row from left to right: Zhiqing Yang, Dunyi Liu, Baoying Zheng, Yuruo Shi, Chun Yang, Chen Wang, Guangshen Ni, Liqin Zhou, Hangqiang Xie, Chunyan Dong, Hui Zhou, Mingzhu Ma, Huiyi Sun, Wei Zhang, Bai Li. Back row from left to right: Biao Song, Yusheng Wan, Shoujie Liu, Ping Jian, Yanbin Wang, Tao Long, Ning Li, Runlong Fan, Yuhai Zhang, Jianhui Liu. 
Centre was only possible through the amazing reliability and performance of the instrument, coupled with a high level of service and maintenance. SHRIMP II generally runs 24 hours a day through the entire year with a 12 hour service-and-maintenance break every week or so. This resulted in an average of about 270 days running per year over the period 2002-2010.

The vast majority of SHRIMP II analyses is on zircons for dating rocks from early Archaean and even Hadean to the very young terranes. The oldest zircons dated at $4.3 \mathrm{Ga}$ came from the famous Jack Hills conglomerate in Western Australia, and the youngest grains, only 1 Ma old, were from Japan and Taiwan. SHRIMP zircon ages have helped to resolve countless geological problems worldwide and were instrumental in establishing a reliable chronostratigraphy for the rock record in China with emphasis on the Precambrian. The laboratory has also played a major role in important Chinese projects such as evolution and tectonic subdivision of the North and South China cratons, deep drilling into the Dabie-Sulu ultra-high pressure metamorphic terranes, proposed delamination of the subcontinental lithosphere beneath the North China Craton, the evolution of orogenic belts in China and general problems of lithospheric composition and evolution. Researchers of the BSC and their Chinese and foreign collaborators have also participated in numerous national and international programs. Recent highlights of BSC research and international collaboration were the dating of impact breccias from the Apollo 12 and 14 missions to the Moon and a lunar meteorite as well as stable isotope work on conodonts from China to establish temperature changes in the Permo-Triassic ocean water.

In 2005 Dunyi Liu and his technical staff installed SROS (SHRIMP Remote Operation System) which was jointly developed by BSC, the National Institute of Meteorology of China and Jilin University in Changchun. The methodology is based on the principle of sharing large scientific instruments, and scientists can observe their samples, operate the SHRIMP and obtain analytical data from locations wherever the system is installed. Also, several scientists from different locations participating in joint experiments can exchange ideas through video and voice in real time, and online access to SHRIMP is particularly useful and cost-saving for students who are far away from the facility. SROS has now been established at two

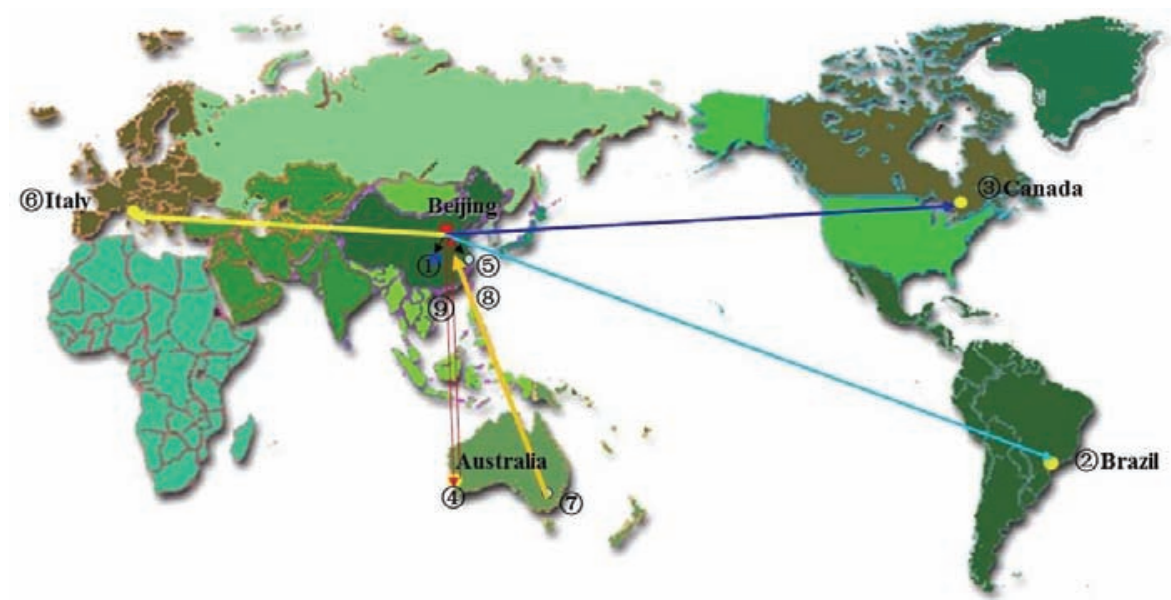

Figure. 3. Map showing links of the Beijing SHRIMP Centre through SROS with other laboratories world-wide. 1 = Yichang Institute of Geology and Mineral Resources, China; 2 = University of Sao Baulo, Brazil; 3 = Ontario Geological Survey, Sudbury, Canada; 4 = Curtin University, Perth, Australia; 5 = Nanjing University, China; $6=$ University of Milan-Bicocca, Italy; 7 = Australia Scientific Instruments Pty. Ltd., Canberra; 8 =Academia Sinica, Taipei, Taiwan; 9 = The Univewrsity of Hong Kong, China.

universities in China (Nanjing and Hong Kong); at the Yichang Institute of Geology and Mineral Resources of the China Geological Survery; the University of Sao Paulo, Brazil; the Ontario Geological Survey in Sudbury, Canada; Curtin University in Perth, Australia; the University of MilanBicocca in Italy; Australian Scientific Instruments Pty. Ltd. in Canberra, Australia; and Academia Sinica in Taipei, Taiwan (Fig.3). During 2007-2010 a total of 393 days of analytical SHRIMP time using SROS world-wide have proven the efficiency and popularity of this system.

In 2007 a second SHRIMP IIe equipped with a multiple collectors was ordered and was completed for delivery to China in 2009. It is still in Canberra until a new laboratory building in Beijing is completed, but can be used remotely through SROS. In 2009, due to declining scientific activities on Precambrian rocks in China over the last 10 years or so, partly in view of a change in worldwide scientific focus from hard rock geology to surface and climate processes, Director Liu and the Institute of Geology of CAGS established the International Precambrian Research Centre of China (IPRCC). This has distinguished Chinese and foreign core members and promotes research on major unresolved global geological issues in the Precambrian and their relevance to Chinese geology and mineral deposits. Field workshops were held in association with foreign collaborators in South Africa in 2010 and South Korea in 2011, and highly successful and popular training courses for
Chinese students and young researchers were conducted in Beijing on zircon geochronology and isotopes (October 2010) and on lithospheric evolution through geologic time (April 2011). The next IPRCC training course on migmatites will be held in October 2012, followed by a field workshop and excursion to the Shandong Peninsula. In October 2010 the BSC hosted the 5th International SHRIMP User Meeting, combined with a workshop on zircon geochronology, that was attended by more than 100 Chinese and foreign scientists.

Current activities of the Beijing SHRIMP Centre include the development of key parts for a Time-of-Flight (TOF) high massresolution secondary ion mass spectrometer. Everybody in the Centre is aware of the fact that the Internet has and will change our lifestyles and the way we work and, no doubt, will result in a totally new way of conducting integrated scientific research. The Centre is at the forefront of this development and will hopefully play a leading role in international earth science research in the next ten years of its activity. Director Liu continues to insist on an open door and sharing philosophy, and thus international scientists are invited to visit the Centre and collaborate with its staff in undertaking high-resolution isotopic research.

\section{Alfred Kroener}

E: kroener@uni-mainz.de

\section{Prof. Liu Dunyi}

E:liudunyi@bjshrimp.cn 